\title{
Multivariate Volatility Modeling of Electricity Futures
}

Luc Bauwens*

Christian M. Hafner* Diane Pierret*

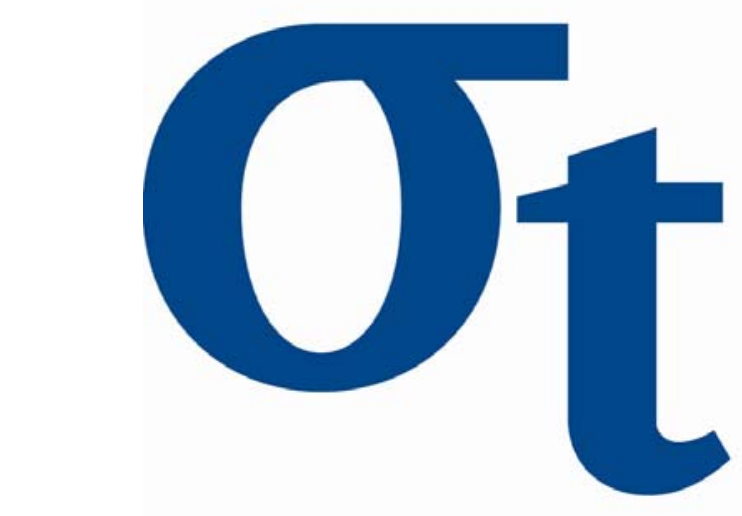

* Université catholique de Louvain, Belgium

$\underline{v}$

u

$\bar{\alpha}$

This research was supported by the Deutsche Forschungsgemeinschaft through the SFB 649 "Economic Risk".

http://sfb649. wiwi. hu-berlin. de ISSN 1860-5664 


\title{
MULTIVARIATE VOLATILITY MODELING OF ELECTRICITY FUTURES
}

\author{
Luc Bauwens ${ }^{1}$, Christian Hafner ${ }^{2 *}$, and Diane Pierret $^{3}$
}

October 13, 2011

\begin{abstract}
We model the dynamic volatility and correlation structure of electricity futures of the European Energy Exchange index. We use a new multiplicative dynamic conditional correlation (mDCC) model to separate long-run from short-run components. We allow for smooth changes in the unconditional volatilities and correlations through a multiplicative component that we estimate nonparametrically. For the short-run dynamics, we use a GJR-GARCH model for the conditional variances and augmented DCC models for the conditional correlations. We also introduce exogenous variables to account for congestion and delivery-date effects in short-term conditional variances. We find different correlation dynamics for long and short-term contracts and the new model achieves higher forecasting performance compared to a standard DCC model.
\end{abstract}

Keywords: electricity futures, dynamic conditional correlations, forecasting, multiplicative component.

JEL Classification: C32, C53, C58.

\footnotetext{
*Correspondence to: Christian Hafner, ISBA, 20 Voie du Roman Pays, B-1348 Louvain-La-Neuve, Belgium. Tel.: +32 104743 06; fax: +32 104730 32; e-mail: christian.hafner@uclouvain.be

${ }^{1}$ Université catholique de Louvain, CORE.

${ }^{2}$ Université catholique de Louvain, ISBA and CORE.

${ }^{3}$ Université catholique de Louvain, ISBA.

The authors thank Jonathan Cornelissen for his interesting discussion at the AFI Finance Workshop at the KULeuven, the participants of the econometrics seminar at CREATES (University of Aarhus), Niels Haldrup and Almut Veraart in particular, the participants of the 65th European Meeting of the Econometrics Society (ESEM 2011), of the econometrics meeting of the Verein für Socialpolitik, and of the 4th international conference on Computational and Financial Econometrics (CFE'10) for their questions and useful comments.

This research was supported by the contract "Projet d'Actions de Recherche Concertées" 07/12-002 of the "Communauté francaise de Belgique", granted by the "Académie universitaire Louvain", and by the Deutsche Forschungsgemeinschaft, SFB 649 Economic Risk. This text presents research results of the Belgian Program on Interuniversity Poles of Attraction (IAP nr. P6/03) initiated by the Belgian State, Prime Minister's Office, Science Policy Programming.
} 


\section{Introduction}

The empirical literature on electricity markets has mainly focused on analyzing and modeling the behavior of spot prices. ${ }^{1}$ However, due to the intrinsic nature of electricity - non-storability, generation constraints, transmission constraints, seasonality and weather dependence - futures represent a larger market than spot trading. Energy risk management uses futures to hedge against spot price fluctuations during the delivery period. Futures contracts are sold and bought to lock the price in advance for the planned generation or consumption of the next years, quarters and months so that spot trading is only used to optimize the procurement and sale of power in the short-run. Futures are also the most natural vehicles for investors willing to take positions in power markets without the underlying physical constraints.

The behavior of power prices is very specific and the absence of an empirical relationship between spot and futures time series motivates us to use a separate model for futures prices. These futures contracts constitute the main part of power investors' portfolios and show evidence of high risk concentration. Quantifying the level of risk concentration is crucial for risk management. Ignoring the interdependences between the portfolio components could lead to wrong allocation or hedging strategies in front of a wrong picture of aggregated risk. With this background, we consider that it is adequate to model jointly the dynamics of volatilities and correlations of three electricity futures contracts written on the index of the European Energy Exchange (EEX), corresponding to monthly, quarterly, and yearly maturities.

We propose a new multivariate volatility model that allows both for smooth changes in the unconditional volatilities and correlations, and for conditional volatility and correlation clustering around the smoothly changing level. The unconditional component correspond to long-run effects, and the conditional one to short-run dynamic effects. The unconditional covariance matrix is specified nonparametrically as a smooth function of time, while the conditional component is specified as a generalized dynamic conditional correlation (DCC) process. ${ }^{2}$ The model has a multiplicative structure, such that the long-run component is estimated by a kernel method, and the short-tun DCC by quasi-maximum likelihood on the data purged from the long-run component. ${ }^{3}$

Applying our multiplicative DCC (mDCC) model to the EEX electricity futures contracts, we find that the unconditional covariance matrix of the futures returns is varying over time. If this variation is neglected, the persistence of conditional variances and correlations is spuriously high. We also find that short-term (conditional) and long-term (unconditional) dynamics follow the evolution of different fundamentals. Short-term dynamics reflect generation, transmission, and demand shocks

\footnotetext{
${ }^{1}$ See e.g. Carnero et al. (2007), Haldrup and Nielsen (2006), De Jong and Schneider (2009), and Bosco et al. (2010).

${ }^{2}$ See Engle (2002) for the DCC model, and Hafner and Franses (2009) for the generalized version.

${ }^{3}$ Other GARCH models that deal with smooth changes in levels of variances and correlations are those of Engle and Rangel (2008) and Rangel and Engle (2009), who use spline functions. Hafner and Linton (2010) propose a multiplicative model of the covariance matrix where the unconditional component is estimated nonparametrically and the conditional component is a BEKK process. Our model can be viewed as a DCC alternative to the latter.
} 
in the physical spot market. Inspired by Haldrup and Nielsen (2006), we introduce congestion effects to account for transmission shocks in the conditional variances of electricity futures. We also account for deterministic patterns associated with the delivery date of short-term contracts. Long-term dynamics are more concerned with long-term trends in energy and financial markets. We finally find that the forecasting performance of the mDCC model is improved compared to the model that ignores the changing level of the long-term component.

The paper is structured as follows: in Section two, we provide a description of the EEX market and we present the data of EEX futures prices that we use. In Section three, we introduce the multiplicative DCC model. We apply this model to EEX futures in Section four. In the fifth section, we discuss the forecasting performance of the new model compared to the standard DCC process, and we conclude in the last section. Additional results are included in an online appendix.

\section{The European Energy Exchange and electricity futures prices}

The oldest electricity wholesale trading market is the Scandinavian market Nord Pool that was the first to introduce electricity futures contracts in 1997 (see www.nasdaqomxcommodities.com). Most papers dealing with electricity prices are referring to Nord Pool prices because of the exemplary efficiency of the market and the availability of price series over long time horizons. Besides, the European Energy Exchange (EEX) has recently become the leading energy exchange in continental Europe in terms of sales and number of trading participants (see www.eex.com). EEX is the result of a merger between the power exchanges in Leipzig and Frankfurt in 2002. Now based in Leipzig, the exchange is a platform for trading in power, natural gas, emission rights and coal.

In 2008, the EEX power spot market concluded a joint venture with its French counterpart Powernext to create the EPEX spot market for France, Germany/Austria and Switzerland. The European Electricity Index (ELIX) was launched in October 2010 as the new market index in an integrated European market. However, we prefer to use a more established index that has become the reference in Germany and most of Europe: the Physical Electricity Index (Phelix). Phelix Base is the arithmetic mean of twenty-four spot prices, each characterizing in Euros the price of one MWh today delivered the next day in the market area Germany/Austria. To take account of intraday patterns, Phelix Peak is the average of the twelve peak load hour spot prices from 8 am until $8 \mathrm{pm}$ for the same market area.

Spot prices are determined through daily auctions by matching supply and demand curves. The supply curve for electricity is constructed such that each generation unit is stacked, ranked from the lowest (hydropower and nuclear plants) to the highest (less efficient plants and peakers) marginal generation cost (Geman (2005), p. 256). The characteristic of the resulting curve (also called power stack function or merit order of electricity) is its convexity since it becomes steeper when production moves to more expensive generation units, during peak hours for example. The shape of the supply curve is therefore mainly technology-driven (plant efficiency) but economic factors such as the price 
of primary energies (e.g. gas, oil, coal) also have an impact either on the level of the curve (general price movement) or on the merit order. On the demand side, the level of demand is sensitive to weather and human activity such that it exhibits daily, weekly and yearly patterns. Despite the recent deregulation and the following increase of competition in electricity markets, the demand curve remains inelastic, as electricity is an essential commodity for human activity.

In commodity markets the mean reversion rate of prices is a function of the speed of adjustment of the supply side to 'events' in the market (Pilipovic (2007), p. 24). Because electricity is nonstorable, supply and demand have to match at any time. For this reason, daily power spot prices tend to exhibit very strong mean reversion and high volatility. Jumps in electricity spot prices are caused by physical events such as plant outages creating sudden abrupt changes in the shape of the power stack function, or heat waves on the demand side. Because of the convex shape of the power stack function, spot price jumps tend to occur more frequently to the upside followed by a rapid opposite movement towards the mean level.

Another important specificity of the electricity market is its transmission network as there is no alternative to it for the transportation of electricity. Haldrup and Nielsen (2006) suggest that transmission constraints between interconnected regions may strongly impact the spot price dynamics. Indeed, the price formation is different whether there is congestion or not between interconnected zones operated by different Transmission System Operators (TSO). ${ }^{4}$ Normally, spot prices are determined by means of separate auctions for each zone. For example, Germany/Austria is considered as a joint market area, except in case of congestion between TSO zones.

Next to the spot market, EEX operates a market for power derivatives in Germany and France. Power derivatives are traded both over-the-counter (OTC) and on exchanges. Although OTC transactions represent the largest volume in the EEX market, we are interested in standardized contracts for their high liquidity and the transparency of their prices. Futures with cash settlement (Phelix futures), futures with physical settlement (Power futures) and options on financial futures (Phelix options) are traded at EEX. For Power futures the delivery of power during base or peak load hours at a specified TSO zone constitutes the underlying asset.

In this paper, we consider the price series of three Phelix baseload futures contracts corresponding to monthly, quarterly and yearly maturities with respective delivery periods. The futures are traded for the current and the next nine months (month future), for the next eleven quarters (quarter future) and for the next six years (year future). It seems however relevant to focus on front contracts that account for the majority of futures trading activity at EEX (Wilkens and Wimschulte (2007)). Month contracts are fulfilled by cash settlement where the settlement price is the Phelix Base monthly index, the arithmetic mean of Phelix Base indices for the delivery month. Quarter and year futures contracts are fulfilled by cascading. Cascading means the automatic splitting of

\footnotetext{
${ }^{4}$ The TSO is an independent organization responsible for the efficient supply of the total demand of electricity in a particular region. After the deregulation and the following unbundling of vertically integrated power companies in Europe, the TSO remains a regulated entity in order to ensure non-discriminatory access to the grid.
} 
long-term contracts into contracts with the next shortest maturity/delivery period which together total the volume of the long-term contract (Geman (2005), p. 274). For example, three trading days before January 2005 the 2005-year future is divided into three month futures for January, February and March and three quarter futures for the second, third and fourth quarters. Then, three trading days before April the second quarter contract is divided into April, May and June futures, etc.

The database consists of three daily price series composed of successive nearest contracts over the period 07.01.2002 until 04.14.2010 (yielding 1963 observations). ${ }^{5}$ These continuous futures prices and returns (adjusted for contract switches) are depicted in Figure 1. Descriptive statistics for the percentage returns of Phelix Base monthly index and Phelix Base futures prices are available in an Appendix (available online). The standard deviations of returns are decreasing when maturity increases from one day (spot index) to one year (year future). A linear relationship between spot and futures returns is not observed, since correlations are comprised between -0.05 and -0.005 . The absence of a clear-cut relationship between observed spot and futures returns motivates our choice to model the futures returns separately from the spot market return.

To simplify estimation, we opt for a two-step approach. In the first step, we model the conditional means of futures returns jointly (see the Appendix). Using the trace rank test of Johansen (1991), we identify two cointegration vectors that represent the month-year and quarter-year spreads. We use therefore a vector error correction model (VECM) to filter the series from their co-movements in the conditional means and from short-run effects. In the second step, developed in the next sections, we model the dynamic volatility and correlation structure of the residuals of the VECM model.
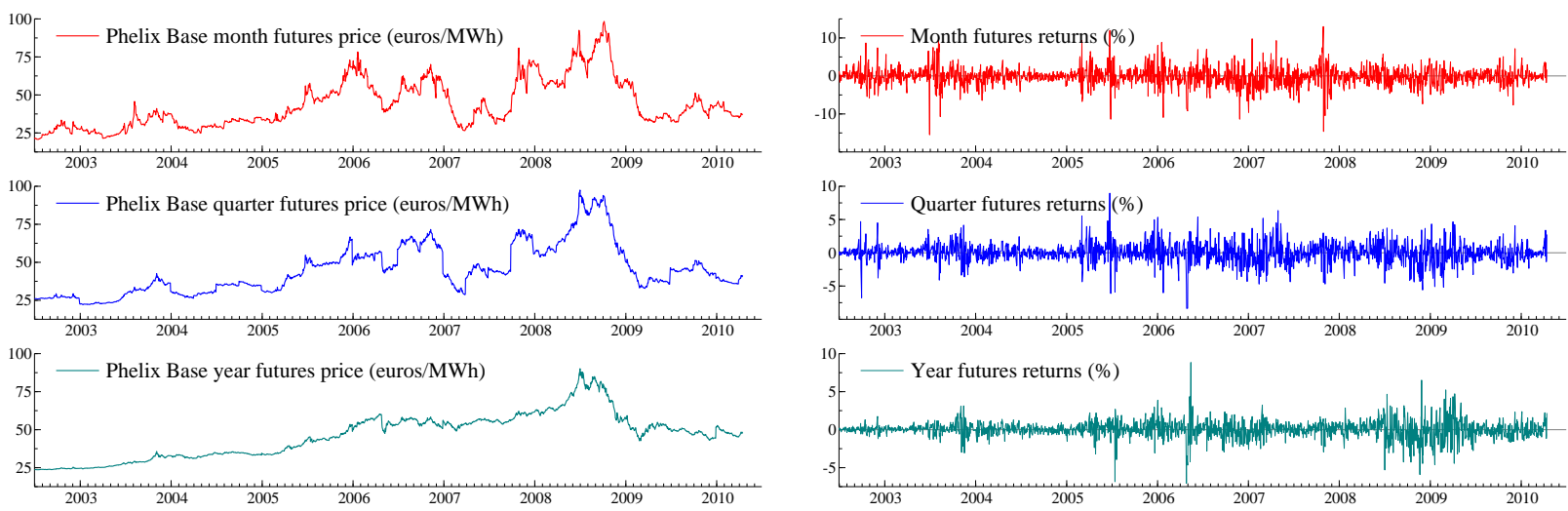

Figure 1: Phelix futures prices and returns (month, quarter, year future)

Multivariate GARCH modeling of the VECM residuals is principally motivated by two observations. First, the autocorrelation functions of squared residuals show evidence of dependence that could be typically captured by a GARCH model. Second, the high positive correlations between

\footnotetext{
${ }^{5}$ Source: Datastream. Series codes: EBMCS00, EBQCS00, EBYCS00.
} 
the residuals - 0.56 for month-year futures, 0.77 for quarter-year, and 0.79 for month-quarter - give a clear incentive to consider a joint model for the volatility of the series.

\section{A Multiplicative DCC model}

\subsection{Motivation and preliminary results}

Multivariate GARCH models are increasingly used thanks to progresses in their specification, the associated inference tools, and their increased availability in econometric software; see the surveys of Bauwens et al. (2006) and Silvennoinen and Teräsvirta (2009). For electricity futures as much as for other financial returns, understanding the co-movements of their second-order moments is important for risk management. Portfolio allocation, risk measures and hedging strategies can be significantly improved by taking into account the correlations between futures of different maturities. By neglecting the existence and the evolution of risk correlations, risk managers may discover that the portfolio diversification or the hedges they thought to have are illusory: "... any VaR analysis will have to assume some relationships between the behavior of forward prices on the same commodity but with different expirations" (Pilipovic (2007), p. 418).

In the following, we use multivariate GARCH models for the volatility matrix of the vector $\epsilon_{t}=\left(\epsilon_{M t}, \epsilon_{Q t}, \epsilon_{Y t}\right)^{\prime}$ of the VECM residuals of the electricity futures returns defined in the previous section ( $\mathrm{M}$ for monthly, $\mathrm{Q}$ for quarterly, and $\mathrm{Y}$ for yearly). These residuals can be interpreted as the shock (or news) components of the returns. ${ }^{6}$ In general, a multivariate GARCH model for $T$ observations on a vector $\epsilon_{t}$ of $n$ elements is defined by

$$
\epsilon_{t}=H_{t}^{1 / 2} z_{t}, \quad z_{t} \sim \operatorname{iid}\left(0, I_{n}\right), \quad t=1,2, \ldots, T,
$$

where $H_{t}^{1 / 2}$ is any $n \times n$ full rank matrix such that $\operatorname{Var}\left(\epsilon_{t} \mid \mathcal{F}_{t-1}\right)=H_{t}^{1 / 2}\left(H_{t}^{1 / 2}\right)^{\prime}=H_{t}$. The model definition is completed by specifying the information set $\mathcal{F}_{t-1}$ and the way in which the conditional covariance matrix $H_{t}$ depends on $\mathcal{F}_{t-1}$ through a finite number of parameters. By default, $\mathcal{F}_{t-1}$ is the sigma-field generated by $\left\{\epsilon_{t-1}, \epsilon_{t-2}, \ldots\right\}$ but it may be augmented by additional variables as we do in Section 4.2 .

Several specifications for $H_{t}$ were tested ${ }^{7}$ and a ranking according to the Bayesian and Akaike information criteria revealed the DCC model of Engle (2002) and the corrected DCC (cDCC) model of Aielli (2009) to outperform the other models for our series. For this reason, the results we present in this paper are based on this class of models. In conditional correlation models, the conditional covariance matrix $H_{t}$ is expressed as $D_{t} R_{t} D_{t}$, where $D_{t}=\operatorname{diag}\left(h_{11 t}^{1 / 2}, \ldots, h_{n n t}^{1 / 2}\right)$ collects

\footnotetext{
${ }^{6}$ If we model the volatility of the futures returns themselves, instead of the VECM residuals, the estimates reported in this paper hardly change, as illustrated in the Appendix (see Tables 3-6).

${ }^{7}$ BEKK (Engle and Kroner (1995)), CCC (Bollerslev (1990)), DCC (Engle (2002)), TVC (Tse and Tsui (2002)), O-GARCH (Alexander (2002)), GO-GARCH (van der Weide (2002)), and cDCC (Aielli (2009)). See Table 2 in the Appendix.
} 
the conditional variances on its diagonal, and $R_{t}$ is the conditional correlation matrix. If the distribution of $z_{t}$ in (1) is assumed Gaussian, the DCC model lends itself to a two-stage quasimaximum likelihood (QML) estimation procedure, where in the first stage the parameters of the conditional variance processes are estimated. In the second stage, the parameters of the conditional correlation process are estimated conditionally on the estimates obtained in the first stage.

In the first stage, information criteria decrease when we replace the standard $\operatorname{GARCH}(1,1)$ specification by the asymmetric GJR-GARCH model of Glosten et al. (1993). A negative estimated GJR parameter is found for month and quarter futures (see results in the Appendix) and suggests the presence of an "inverse leverage" effect, meaning that positive shocks amplify the conditional variance more than equivalent negative shocks. Knittel and Roberts (2005) attribute this effect in electricity returns to the convexity of the power stack function, since positive demand shocks have a larger impact on prices than negative demand shocks.

The second stage is devoted to the estimation of the conditional correlation parameters. The DCC process is defined for the $Q_{t} n \times n$ symmetric positive-definite matrix by

$$
Q_{t}=(1-a-b) \bar{Q}+a u_{t-1} u_{t-1}^{\prime}+b Q_{t-1},
$$

where $a$ and $b$ are scalar parameters (restricted by $a+b<1, a>0, b \geq 0), u_{i t}=\epsilon_{i t} / \sqrt{h_{i i t}}(i=$ $1,2, \ldots, n)$ are the "degarched" errors, and $\bar{Q}$ is a positive-definite parameter matrix. Conditional correlations are obtained by transforming $Q_{t}$ to $(\odot$ denoting the Hadamard product)

$$
R_{t}=\left(I_{n} \odot Q_{t}\right)^{-1 / 2} Q_{t}\left(I_{n} \odot Q_{t}\right)^{-1 / 2}
$$

The parameter $\bar{Q}$ can be estimated by the sample covariance matrix of $u_{t}$ and concentrated out of the likelihood function. However, Aielli (2009) notices that this method-of-moment estimator of $\bar{Q}$ is inconsistent. He proposes a corrected specification of $Q_{t}$ known as the cDCC model, such that the empirical covariance of the corrected $u_{t}$ is consistent for $\bar{Q}$. For our data, the DCC and cDCC models are however empirically very similar; only a slight increase of the likelihood value (from 1949.18 to 1952.83$)$ is observed in favour of the cDCC model. ${ }^{8}$

Our empirical results based on the standard DCC model underline the need for a more flexible modeling of the conditional variances and correlations. For example, the estimates of the univariate variance processes (see Tables 3 and 4 in the Appendix) imply a persistence measure larger than one and the non-existence of the unconditional variances. The persistence of shocks in correlations is also high $(\hat{a}+\hat{b}=0.96)$, and estimations on subsamples give different unconditional correlation levels. Moreover, we observe that bivariate DCC estimations lead to very different results for the $a$ and $b$ parameters of each correlation (see Table 5 in the Appendix). We are therefore interested in introducing flexibility in two directions: (1) time-varying unconditional variance and correlation

\footnotetext{
${ }^{8}$ As for the conditional variances, the (c)DCC process may be specified to include asymmetric effects, see Cappiello et al. (2006). These effects are not significant at the $5 \%$ level for our data and are therefore not included in our models.
} 
levels, and (2) asset-specific correlation dynamics.

Developments of this kind are recent and show the growing interest of flexible modeling of multivariate volatility. On item (1), extensions of the univariate GARCH model to deal with spurious persistence have been proposed, such as component (Engle and Lee (1999); Bauwens and Storti (2009)), regime switching (Haas et al. (2004b); Bauwens et al. (2010)), mixture (Haas et al. (2004a)) and spline (Engle and Rangel (2008)) GARCH models. In the multivariate context, several proposals deal with changing levels in unconditional correlations such as the regime switching dynamic correlation model of Pelletier (2006), the component DCC model of Colacito et al. (2009), the smooth transition conditional correlation model of Silvennoinen and Teräsvirta (2005), the factorspline-GARCH DCC model of Rangel and Engle (2009), and the multiplicative BEKK model of Hafner and Linton (2010). For item (2), asset-specific parameters for dynamic conditional correlations have been introduced in the quadratic flexible DCC model of Billio and Caporin (2009) and the generalized DCC model of Hafner and Franses (2009).

\subsection{The model and its estimation}

The strong persistence found in conditional variances and correlations, and the instability of the unconditional covariance matrix estimates over different subsamples suggest that the standard DCC model should allow for changes in the unconditional volatilities and correlations. These changes are probably induced by different factors affecting the market environment and structure, such as changing energy prices, growing market size, new technologies, the arrival of new market participants and new products, and other elements.

The idea behind the multiplicative DCC (mDCC) model is to decompose the conditional covariance matrix of $\epsilon_{t}$ into a component that can change smoothly over time, and another component that captures the short-run dynamic structure typical of multivariate GARCH processes. To achieve this, the square root matrix $H_{t}^{1 / 2}$ in (1) is itself written as the product of two square root matrices $\Sigma(t / T)^{1 / 2}$ and $G_{t}^{1 / 2}$ such that

$$
H_{t}=\Sigma(t / T)^{1 / 2} G_{t}^{1 / 2}\left(G_{t}^{1 / 2}\right)^{\prime}\left[\Sigma(t / T)^{1 / 2}\right]^{\prime}=\Sigma(t / T)^{1 / 2} G_{t}\left[\Sigma(t / T)^{1 / 2}\right]^{\prime}
$$

is positive-definite and symmetric. The matrix $G_{t}$ is specified as a DCC process to capture the short-run GARCH dynamics. ${ }^{9}$ By assuming that $\mathrm{E}\left(G_{t}\right)=I_{n}$ (for identification), it follows that

$$
\operatorname{Var}\left(\epsilon_{t}\right)=\mathrm{E}\left(H_{t}\right)=\Sigma(t / T)^{1 / 2} \mathrm{E}\left(G_{t}\right)\left[\Sigma(t / T)^{1 / 2}\right]^{\prime}=\Sigma(t / T),
$$

so that $\Sigma(t / T)$ is the unconditional "long run" covariance matrix that is assumed to be a deterministic and smooth function of time.

\footnotetext{
${ }^{9}$ Hafner and Linton (2010) use the BEKK model in the same multiplicative structure as above. We use the DCC because it provides a better fit for our data. Apart from empirical considerations, the DCC and BEKK models have their respective advantages.
} 
Regarding estimation, the idea behind this semiparametric model is to combine the nonparametric estimation of the unconditional covariance matrix with the two-stage QML estimation of the parameters of the DCC component. Hence, the estimation procedure comprises three stages.

At the first stage, the unconditional covariance matrix can be estimated by the Nadaraya-Watson estimator (or other nonparametric estimators) applied to the $\epsilon_{t}$ data (the VECM residuals):

$$
\hat{\Sigma}(\tau)=\frac{\sum_{t=1}^{T} K_{h}\left(\frac{t}{T}-\tau\right) \epsilon_{t} \epsilon_{t}^{\prime}}{\sum_{t=1}^{T} K_{h}\left(\frac{t}{T}-\tau\right)},
$$

where $\tau \in[0,1], K_{h}(\cdot)=(1 / h) K(\cdot / h), K(\cdot)$ is a kernel function, and $h$ is a positive bandwidth parameter. Unconditional correlations are then estimated by

$$
\hat{\rho}_{i j}(\tau)=\frac{\hat{\Sigma}_{i j}(\tau)}{\sqrt{\hat{\Sigma}_{i i}(\tau) \hat{\Sigma}_{j j}(\tau)}} .
$$

The standardized residuals derived from the first stage estimation, defined by $\xi_{t}=\Sigma(t / T)^{-1 / 2} \epsilon_{t}$, have as unconditional covariance the identity matrix, and as conditional covariance the matrix $G_{t}$, i.e. $\mathrm{E}\left(\xi_{t} \xi_{t}^{\prime}\right)=I_{n}$ and $\mathrm{E}\left(\xi_{t} \xi_{t}^{\prime} \mid \mathcal{F}_{t-1}\right)=G_{t}$.

At the second stage, the conditional variance parameters for the elements of $\xi_{t}$ are estimated by QML. As for the standard DCC model, any univariate GARCH process satisfying appropriate stationarity conditions and non-negativity constraints can be used. We use for our application in Section 4 the GJR model with $\xi_{i t}$ as shock, and imposing a unit variance:

$$
g_{i i t}=\left(1-\alpha_{i}-\beta_{i}-0.5 \gamma_{i}\right)+\alpha_{i} \xi_{i t-1}^{2}+\beta_{i} g_{i i t-1}+\gamma_{i} \xi_{i t-1}^{2} I_{\left\{\xi_{i t-1}<0\right\}},
$$

where $g_{i i t}=\operatorname{Var}\left(\xi_{i t} \mid \mathcal{F}_{t-1}\right)$ and $I_{\left\{\xi_{i t}<0\right\}}$ is a dummy variable equal to one when the past shock is negative. The constant term $\left(1-\alpha_{i}-\beta_{i}-0.5 \gamma_{i}\right)$ ensures that $g_{i i t}$ is standardized to have an unconditional mean equal to one. The Gaussian log-likelihood for stage two is

$$
\ell_{2}=-\frac{1}{2} \sum_{i=1}^{n} \sum_{t=1}^{T}\left[\log \left(g_{i i t}\right)+\frac{\xi_{i t}^{2}}{g_{i i t}}\right] .
$$

The second-stage "degarched" residuals, defined by $u_{t}=D_{t}^{-1} \xi_{t}$, where $D_{t}=\operatorname{diag}\left(g_{11 t}^{1 / 2}, \ldots, g_{n n t}^{1 / 2}\right)$, have consequently an identity matrix as unconditional covariance matrix, unitary conditional variances, and are conditionally correlated, i.e. $\mathrm{E}\left(u_{t} u_{t}^{\prime}\right)=I_{n}$ and $\mathrm{E}\left(u_{t} u_{t}^{\prime} \mid \mathcal{F}_{t-1}\right)=R_{t}$, where $R_{t}$ is the conditional correlation matrix.

At the third stage, the parameters of the conditional correlation matrix are estimated. The proposed dynamic correlation structure is a DCC model for the second-stage residuals:

$$
Q_{t}=(1-a-b) I_{n}+a u_{t-1} u_{t-1}^{\prime}+b Q_{t-1}
$$


where $a$ and $b$ are scalar parameters restricted by $a+b<1, a>0$, and $b \geq 0$. Notice that the constant matrix $\bar{Q}$ is restricted to an identity matrix. The conditional correlations are obtained by applying (3). This DCC model à la Engle is not subject to Aielli's critique, since the expectation of $Q_{t}$ (equal to an identity matrix) is equal to the unconditional correlation matrix of $u_{t}$. The Gaussian log-likelihood for stage three is

$$
\ell_{3}=-\frac{1}{2} \sum_{t=1}^{T}\left[\log \left(\left|R_{t}\right|\right)+u_{t}^{\prime} R_{t}^{-1} u_{t}\right] .
$$

Finally, if the model is correctly specified, both unconditional and conditional covariance matrices of the third-stage residuals $\hat{z}_{t}=\hat{H}_{t}^{-1 / 2} \epsilon_{t}$ are asymptotically equal to the identity matrix, so that these residuals can be used for misspecification diagnostics.

The mDCC model presented above is designed to account for a time-varying unconditional covariance matrix. The question of asset-specific correlation dynamics is addressed empirically in Subsection 4.3, where we use the generalized DCC model of Hafner and Franses (2009) in the multiplicative framework.

\section{Application to Phelix futures}

\subsection{Smoothly time-varying unconditional covariance matrix}

The multiplicative DCC model contains a long-term component that is slowly changing over time. The bandwidth parameter $h$ serves to separate the long-term and short-term movements. The smaller the bandwidth, the larger the size of movements that is captured by the long-term component, and the smaller the amplitude of short-term conditional movements.

Several procedures are available to select the bandwidth based on the minimization of quadratic error measures for a regression curve. For nonparametric regression, a common criterion for choosing the optimal bandwidth is the least squares cross-validation criterion. Härdle (1990) shows that the procedure amounts to choosing the bandwidth that minimizes the sum of squared differences between model predictions and observed data, where small values for the bandwidth are penalized. As penalty, we use Rice's function, defined as $(1-2 u)^{-1}$. Since the long-term covariance matrix is not observed, we take a six-month rolling covariance as the reference for the computation of squared differences. The optimal bandwidth is the bandwidth that minimizes this criterion and is equal to 0.05 for a Gaussian kernel.

To assess the quality of fit of long-term variances and correlations, the estimated unconditional levels are compared with alternative measures of long-term variances and correlations. In Figures 2 and 3, we compare the estimated unconditional variances and correlations (black smooth lines) with their six-month realized levels (black dots) and their six-month rolling levels (black discontinuous lines). The light grey lines (with peaks) are the total levels of variances and correlations including 
the unconditional and conditional components. Results of Section 4 and Section 5 are generated using Ox version 6.10 (see Doornik (2009)).
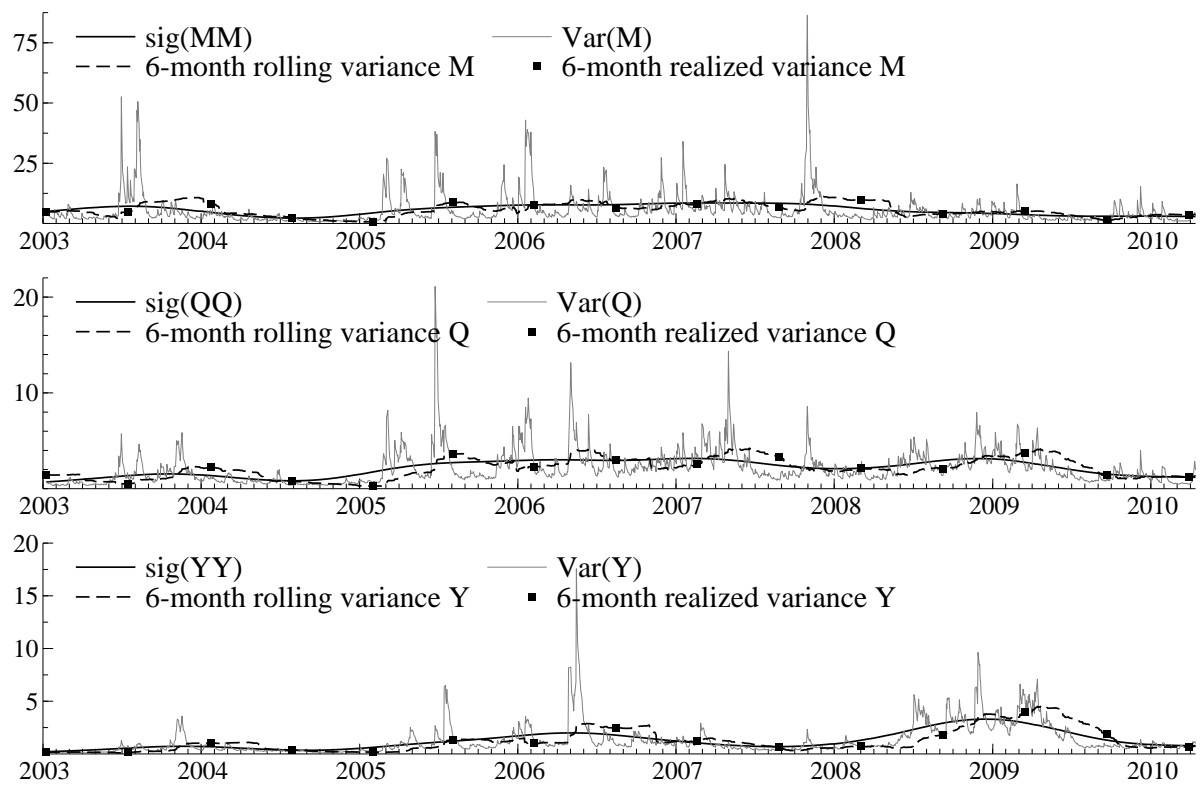

Figure 2: Unconditional variances (month, quarter, year future). The estimated unconditional variance of futures contracts of maturity $i$ is $\operatorname{sig}(i i)=\hat{\Sigma}_{i i, t}$, see (5). The estimated total variance of contract $i$ is $\operatorname{Var}(i)=\hat{H}_{i i, t}$, see (4).

In Figure 4, we present pointwise confidence bands (black dashed lines) at 95\% confidence level for the kernel estimator of the unconditional covariance matrix as defined in Härdle (1990, p. 127). The confidence intervals give a clear indication that unconditional variances and covariances are not constant. Changing regimes in variances and covariances should coincide with structural changes in power markets. During the period 2006-2008, Germany experienced a period of high power consumption growth caused by an increase of residential consumption (with the widespread use of traditional appliances and the introduction of new consumer electronics, information and communication technology equipment). The high power demand led to increasing volumes of traded derivatives on the EEX market. As mentioned above, a strong demand growth increases the volatility of electricity prices. Like for other commodities, a higher volatility may be caused by a probable shortage of the resource. For electricity, a shortage is implied by generation and transmission constraints. 


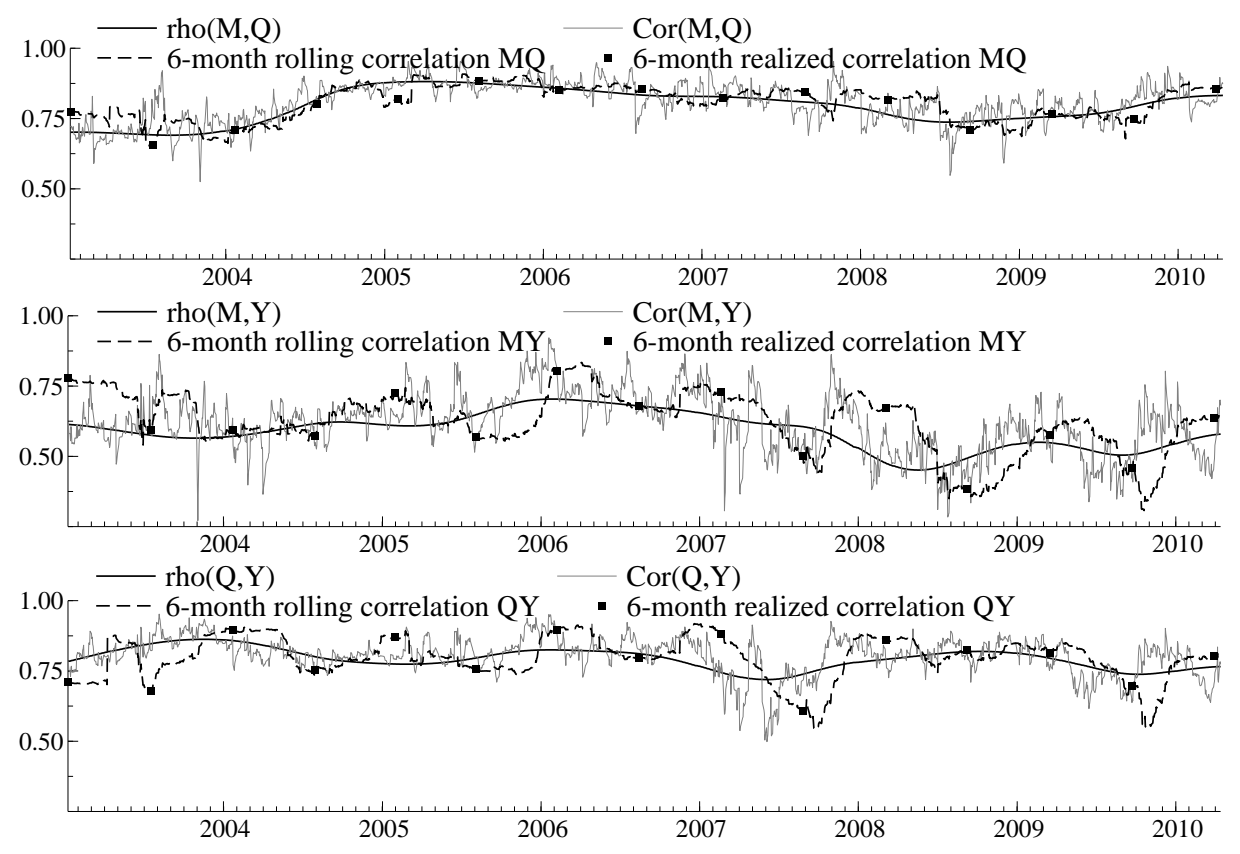

Figure 3: Unconditional correlations (month-quarter, month-year, quarter-year). The estimated unconditional correlation between contracts of maturity $i$ and contracts of maturity $j$ is $r h o(i, j)=\hat{\rho}_{i j, t}$, see (6). The estimated total correlation between contracts $i$ and $j$ is $\operatorname{Cor}(i, j)=\hat{H}_{i j, t} /\left(\hat{H}_{i i, t} \hat{H}_{j j, t}\right)^{1 / 2}$, see (4).
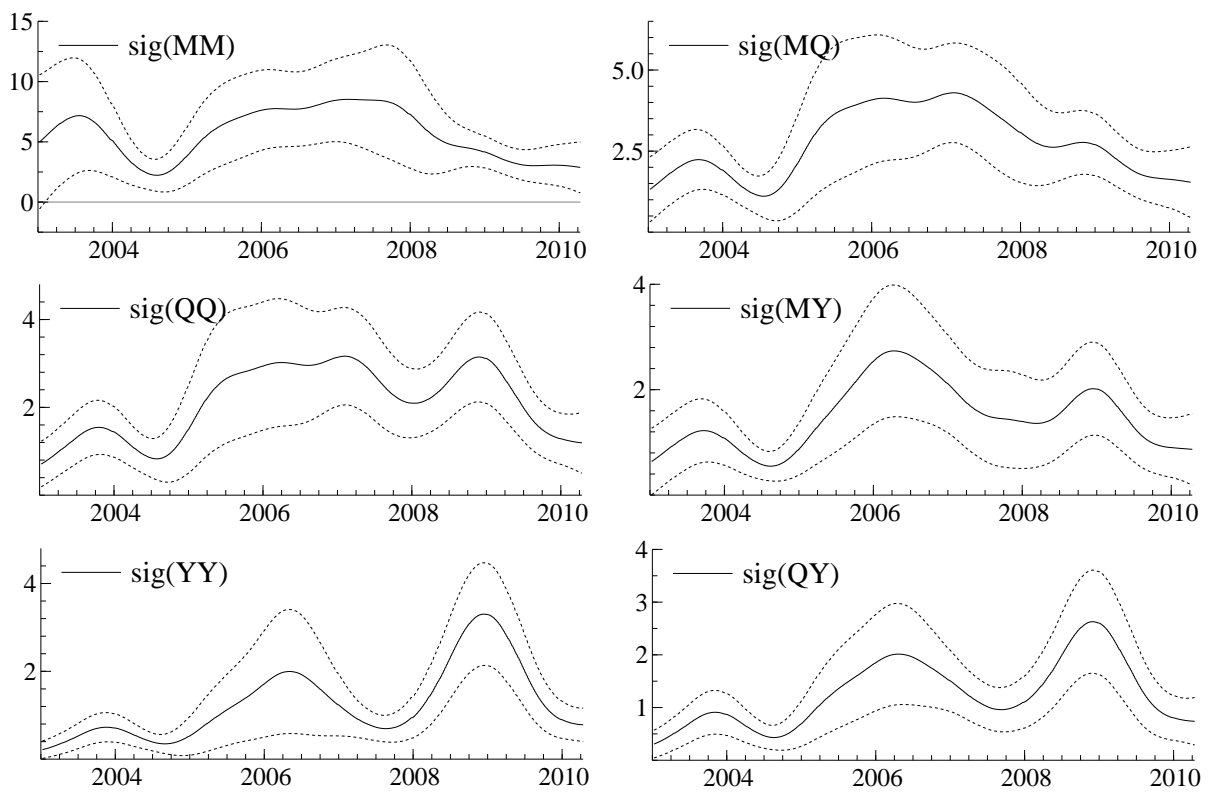

Figure 4: Unconditional variances (left panel) and covariances (right panel), and their 95\%-level confidence intervals. The unconditional covariance of contracts $i$ and $j$ is $\operatorname{sig}(i j)=\hat{\Sigma}_{i j, t}$, see (5). 
Dependence between electricity and natural gas (usually referred as the marginal fuel in the power stack function) was accentuated during the period November 2005 - March 2006. During this period, the correlations between the unconditional variance and covariance estimates of Phelix futures and the estimated long-term variance of the natural gas day ahead returns at the Zeebrugge and National Balancing Point (NBP) hubs are all larger than 0.99. This period corresponds to a sudden increase of European natural gas prices, which led to a surge of EEX on-peak spot prices (Janczura and Weron (2010)). The long-term variances of natural gas day ahead returns at the Zeebrugge and NBP hubs, estimated nonparametrically (by a Gaussian kernel with a bandwidth equal to 0.05 ), are shown on Figure 5. We observe a small volatility bump in 2004 for the NBP natural gas volatility, and a larger bump in 2006, which coincides with increasing natural gas prices and increasing variances and covariances of all Phelix futures contracts.
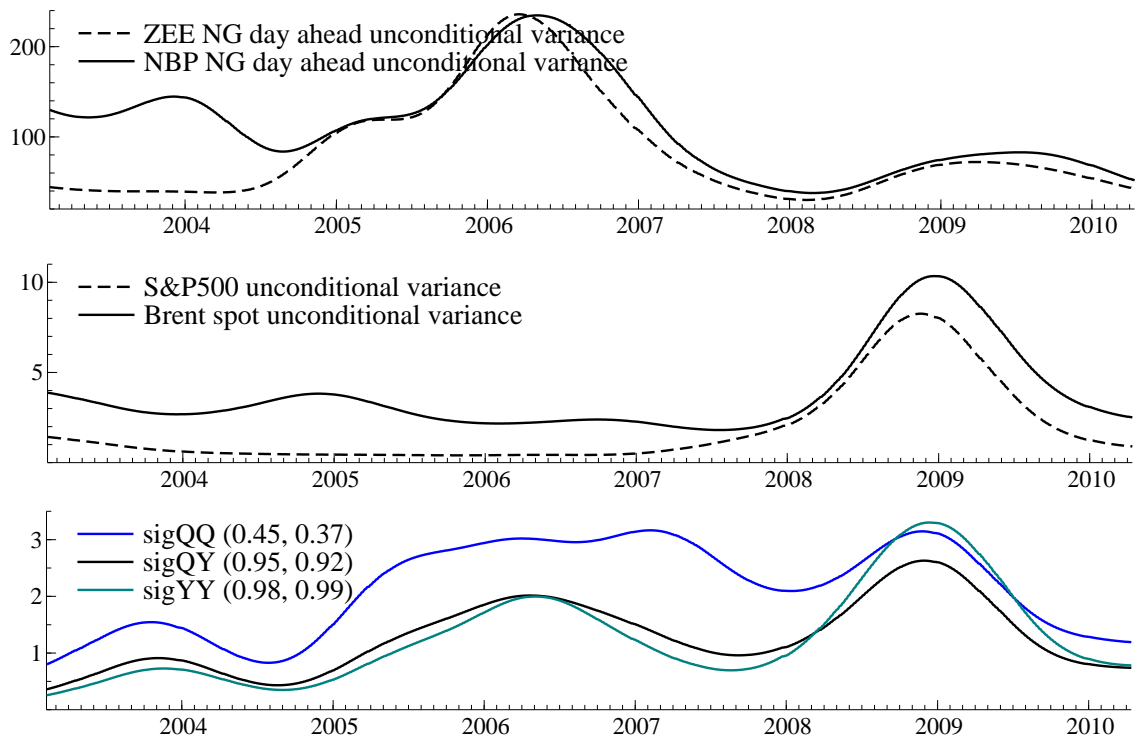

Figure 5: Top panel: Zeebrugge and NBP natural gas day ahead unconditional variance estimates. Middle panel: S\&P500 and Brent spot unconditional variance estimates. Bottom panel: estimates of unconditional variances of quarter and year futures and their covariance. Their correlations with S\&P 500 and Brent unconditional variances are given in parentheses. Correlations are for the period 01.01.2007-04.14.2010.

In 2009, we observe a volatility bump in quarter and year futures, and in their co-volatility, see Figure 5 (bottom panel). In the middle panel, we observe a similar pattern in the volatilities of the S\&P 500 index and of the Brent spot price following the 2008 financial crisis. Nonparametric estimates of the variances of the S\&P 500 and Brent spot returns are taken as proxies for the volatility of the financial and oil markets, respectively. The S\&P 500 volatility reached extreme levels after the announcement of the Lehman Brothers bankruptcy in September 2008. The following economic recession caused oil prices to plummet after a long period of slowly increasing prices. This 
sudden drop induced a maximal volatility of Brent returns in late 2008-early 2009 corresponding to the volatility bump we observe for quarter and year Phelix futures. As a result, the 2009 bump observed for the volatility of quarter and year electricity futures is related to the high volatility of oil prices during the 2008-2009 recession period. As quantitative measure of these relations, the correlations between the unconditional variances of the long-term electricity futures contracts and the S\&P 500 and Brent unconditional variances range from 0.37 to 0.99 during the crisis (see Figure $5)$.

The consumption growth and the evolution of primary energy prices are certainly not the unique elements to explain the long-term levels of the variances and covariances of electricity futures. Other long-term factors may be responsible for these changes, such as political decisions in favor of cleaner electricity, the launch of new generation technologies or the introduction of emission rights changing the merit order, a raising awareness of resource scarcity affecting the risk aversion of investors, and new regulations ensuring the independence of TSOs. The arrival of new market participants, new financial products, mergers, acquisitions and other alliances also change the market structure by rebalancing the actual forces governing the market. The integration of European power exchanges such as the merger of the German and French spot exchanges in 2008 may also have impacted the variance-covariance levels of futures. Risk aversion, market power or the impact of some market trends are however hard to measure quantitatively. For this reason, the nonparametric component of our model is convenient as it is exclusively based on data evidence and does not require identifying and measuring the variables influencing the long-term levels of the variances and covariances.

\subsection{A periodic congestion model for conditional variances}

We turn to the modeling of the conditional variances of the electricity futures. The estimation results of GJR-GARCH $(1,1)$ models within the multiplicative structure and without it show two differences (see Table 3 in the Appendix). First, the persistence of each conditional variance is smaller than one when the multiplicative model is used, while it is larger than one otherwise. Thus, the existence of the unconditional variances is implied by the multiplicative model, contrary to the standard model. Second, the inverse leverage parameters for month and quarter futures are also more negative with the multiplicative model. This effect is not significant for the year future in both models and is therefore not included.

With the decomposition of the variances into long-term and short-term components, we are able to identify variables explaining short-term movements in the volatility of electricity futures. Next to supply and demand shocks, grid transmission shocks may influence the volatility of electricity futures. As already mentioned, the spot price formation at EEX is different whether there is congestion between TSO zones (inside the same market area) or not. Haldrup and Nielsen (2006) model Nord Pool spot prices with directional congestion as the state variable in a regime-switching model. Their proxy for congestion is the difference of spot prices between Nord Pool regions where 
the region with the highest price is the region with excess demand. Moreover, transmission constraints also exist between countries or market areas and may also affect the short-term volatility of electricity futures. We adapt the congestion variable of Haldrup and Nielsen (2006) to account for the impact of international congestion on the conditional variances. The proxy employed for congestion is the squared difference of log baseload or peakload indices between EEX and neighboring markets. ${ }^{10}$ Adding these variables in the GJR process (7), the model is

$$
g_{i i t}=\phi_{i}+\alpha_{i} \xi_{i t-1}^{2}+\beta_{i} g_{i i t-1}+\gamma_{i} \xi_{i t-1}^{2} I_{\left\{\xi_{i t-1}<0\right\}}+\sum_{k=1}^{K} \delta_{i k}\left[\log \left(p_{E E X, t-1} / p_{k, t-1}\right)\right]^{2}+\kappa_{i}\left(T_{M D}-t\right)
$$

where

$$
\phi_{i}=1-\alpha_{i}-\beta_{i}-0.5 \gamma_{i}-\sum_{k=1}^{K} \delta_{i k} T^{-1} \sum_{t=2}^{T}\left[\log \left(p_{E E X, t-1} / p_{k, t-1}\right)\right]^{2}-\kappa_{i} T^{-1} \sum_{t=1}^{T}\left(T_{M D}-t\right),
$$

$p_{k, t-1}$ is the index of market $k$ at date $t-1, K$ is the number of adjacent market areas and $T_{M D}-t$ is the number of days before the first day of the next delivery period of the month future. The parameter $\kappa_{i}$ captures the deterministic effect or periodicity attached to the expiry date of the futures contract. A negative $\kappa_{i}$ is a manifestation of the so-called "Samuelson effect": futures volatilities increase when the contracts approach their maturity date (Samuelson (1965)). The periodicity of the month contract seems to be strongly significant to explain the variances of Phelix month and Phelix quarter returns, since $t$-statistics are less than -4 . The periodicity effect for the year contract is excluded from the yearly futures GJR equation as it is not significant at $5 \%$. ${ }^{11}$ We know that the month future is directly followed by a delivery period while other futures are cascading at maturity. Since the month Phelix contract is still traded during the delivery month we prefer to call this effect a day-to-delivery effect rather than a Samuelson (day-to-maturity) effect.

The congestion variables are lagged by one day to allow for forecasting and their selection is based on BIC minimization for the second stage estimation. The estimation results of the selected congestion models, with the day-to-delivery effect, are presented in Table 1 (left part). The parameter estimates of the periodic congestion models can be compared with the estimates obtained with a GJR model without exogenous variables for the same sample period (right part of Table 1).

The congestion and day-to-delivery parameters in Table 1 are probably all significant at least at the $10 \%$ level. The congestion parameter estimates are all positive and the day-to-delivery ones

\footnotetext{
${ }^{10}$ Neighboring markets: APX for the Netherlands, Nord Pool West and East Denmark, GME for Italy, Powernext for France and the Dow Jones index for Swiss electricity prices. The list is not exhaustive. These price indices are available in Datastream.

${ }^{11}$ Significance is decided using standard Gaussian tests. The standard errors reported in Table 1 (and further tables) are conditional on the VECM estimation and the nonparametric estimation of the first step. Taking account of these previous estimations should in principle increase the estimator variances, though this may not be the case in small samples for estimated variances. Therefore significance test results as we report them must be interpreted with care. However no $t$-ratio implied by Table 1 is smaller than 2.09 in absolute value, so that significance at $10 \%$ at least seems likely for all parameters.
} 
are negative, as expected. The likelihood ratio statistics implied by the results are larger than 8.5 when we include the congestion and day-to-delivery variables. It turns out that different markets influence Phelix futures according to their maturity; the month futures reacts to congestion with Switzerland (Swiss) while the quarter and year futures are subject to transmission shocks during the day from France (FR Peak) and East Denmark (E.DK Peak), respectively.

\begin{tabular}{ccccc}
\hline & \multicolumn{2}{c}{ periodic congestion GJR } & \multicolumn{2}{c}{ GJR } \\
Month Baseload Future & Coefficient & Std. error & Coefficient & Std. error \\
\hline ARCH $(\alpha)$ & 0.250 & 0.029 & 0.285 & 0.037 \\
GARCH $(\beta)$ & 0.747 & 0.032 & 0.709 & 0.041 \\
GJR $(\gamma)$ & -0.116 & 0.035 & -0.117 & 0.039 \\
Congestion $\left(\delta_{\text {Swiss }}\right)$ & 0.193 & 0.087 & - & - \\
Day-to-delivery $(\kappa)$ & -0.007 & 0.001 & - & - \\
\hline Log-likelihood: & -1826.85 & \multicolumn{3}{c}{ GJR } \\
\hline \hline & periodic congestion GJR & -1850.53 & \\
Quarter Baseload Future & Coefficient & Std. error & Coefficient & Std. error \\
\hline ARCH $(\alpha)$ & 0.200 & 0.028 & 0.203 & 0.029 \\
GARCH $(\beta)$ & 0.762 & 0.030 & 0.759 & 0.033 \\
GJR $(\gamma)$ & -0.090 & 0.034 & -0.076 & 0.036 \\
Congestion $\left(\delta_{F R}\right.$ Peak $)$ & 0.431 & 0.206 & - & - \\
Day-to-delivery $(\kappa)$ & -0.008 & 0.002 & - & - \\
\hline Log-likelihood: & -1918.45 & \multicolumn{3}{c}{ GJR } \\
\hline \hline
\end{tabular}

Table 1: Conditional variance parameter estimates for $\xi_{t}$ (multiplicative model). See eq (9) and eq (7). Sample period: $06.23 .2004-04.14 .2010$ (1467 observations)

\subsection{Asset-specific dynamic conditional correlations}

The third and last stage of the estimation procedure consists in the estimation of the process of conditional correlations between pairs of electricity futures contracts. The results reported below are all based on the estimations of the GJR-GARCH processes where congestion and periodicity effects are included. The mDCC estimated parameters are reported in Table 2. The estimate of $a+b$ of the mDCC model (about 0.88) is lower than in the standard DCC model (about 0.95), implying a much smaller persistence of conditional correlations.

We have already mentioned that bivariate estimations for the standard DCC model lead to very different estimates of the parameters for the dynamics of the different pairs of correlations. Although the model was originally conceived for a large number of assets, the generalized DCC 
(GDCC) of Hafner and Franses (2009) also appears to be useful in the present context. The conditional correlation structure of the multiplicative GDCC (mGDCC) model is

$$
Q_{t}=\left(\iota \iota^{\prime}-a a^{\prime}-b b^{\prime}\right) \odot I_{n}+a a^{\prime} \odot u_{t-1} u_{t-1}^{\prime}+b b^{\prime} \odot Q_{t-1},
$$

where $\iota$ is an $(n \times 1)$ vector with each element equal to one, $a$ and $b$ are $(n \times 1)$ vectors of parameters, restricted by $a_{i}^{2}+b_{i}^{2}<1, a_{i}>0$, and $b_{i} \geq 0$. Hence $\left(\iota \iota^{\prime}-a a^{\prime}-b b^{\prime}\right) \odot I_{n}$ is positive-semi-definite for all $a$ and $b$, ensuring a positive-definite $Q_{t}$ (if so is $Q_{0}$ ). Based on non-rejection by a likelihood-ratio test, we consider a simplified version of the GDCC model, where only the elements of $a$ differ:

$$
Q_{t}=\left(\iota \iota^{\prime}-a a^{\prime}-b^{2} I_{n}\right) \odot I_{n}+a a^{\prime} \odot u_{t-1} u_{t-1}^{\prime}+b^{2} Q_{t-1}
$$

where $b$ is now a scalar. The mGDCC parameter estimates are provided in Table 3.

\begin{tabular}{ccc}
\hline mDCC & Coefficient & Std. error \\
\hline$a$ & 0.067 & 0.010 \\
$b$ & 0.812 & 0.031 \\
\hline Log-likelihood: & 38.76 & \\
\hline
\end{tabular}

Table 2: mDCC parameter estimates (eq (8)). Sample period: 06.23.2004-04.14.2010 (1467 observations)

\begin{tabular}{ccc}
\hline mGDCC & Coefficient & Std. error \\
\hline$a_{M}^{2}$ & 0.035 & 0.013 \\
$a_{Q}^{2}$ & 0.116 & 0.036 \\
$a_{Y}^{2}$ & 0.070 & 0.027 \\
$b^{2}$ & 0.804 & 0.031 \\
\hline Log-likelihood: & 41.55 & \\
\hline
\end{tabular}

Table 3: mGDCC parameter estimates (eq (10)). Sample period: 06.23.2004-04.14.2010 (1467 observations)

We show the mDCC and mGDCC short-term conditional correlations of the second stage residuals $u_{t}$ in Figure 6. Notice that they fluctuate around zero since the long-run changing level has been removed by the kernel estimation of the long-run component. While the mDCC correlations have by assumption the same dynamics, we see that the correlations of the mGDCC model exhibit different patterns. For the correlation process between month and quarter futures, there is little change between the $\mathrm{mDCC}$ and $\mathrm{mGDCC}$ correlation processes. Compared to the mDCC parameter estimate $\hat{a}(0.067)$, the mGDCC parameter associated to innovations in the month-quarter correlation process has a slightly lower estimate $\left(\hat{a}_{M} \hat{a}_{Q}=0.064\right)$. This mGDCC parameter is estimated to be much lower for the correlations between month and year contracts $\left(\hat{a}_{M} \hat{a}_{Y}=0.049\right)$ such that the conditional correlation process between these two contracts exhibits the lowest persistence. In quarter-year correlations, we find the highest mGDCC estimated parameter $\left(\hat{a}_{Q} \hat{a}_{Y}=0.09\right)$ and the highest persistence implying amplified movement for short run correlation dynamics. 

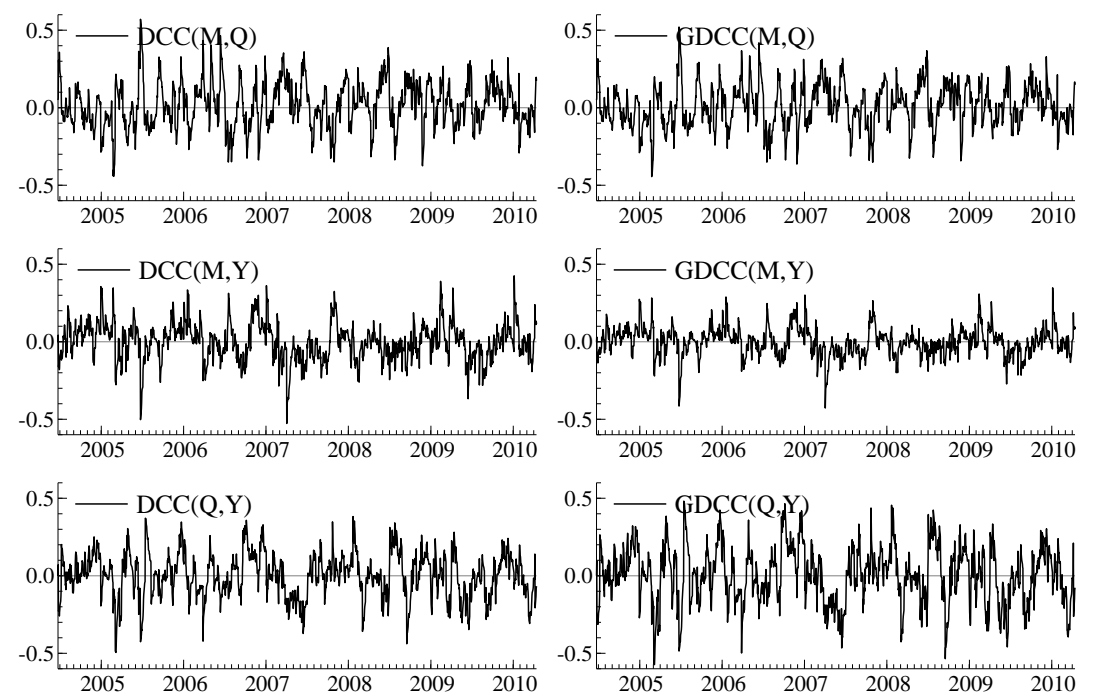

Figure 6: mDCC and mGDCC conditional correlations of $u_{t}$ (month-quarter, month-year, quarter-year). $D C C(i, j) / G D C C(i, j)$ are the conditional correlations between contracts $i$ and $j$ estimated with the $\mathrm{mDCC} / \mathrm{mGDCC}$ model.

We test the lack of autocorrelation in the squared residuals $\hat{z}_{t} \hat{z}_{t}^{\prime}$ (where $\hat{z}_{t}=\hat{H}_{t}^{-1 / 2} \epsilon_{t}$ ) using the multivariate portmanteau statistic. The values of the statistic do not allow us to accept the null hypothesis both for the DCC and multiplicative DCC models. However, the statistic values (about 2500) are substantially reduced compared to its value (25143) for the VECM squared residuals $\left(\epsilon_{t} \epsilon_{t}^{\prime}\right)$. To compare the multivariate volatility models in terms of in-sample fit, we look at the total log-likelihood value, $\hat{\ell}=-0.5\left[\sum_{t=1}^{T} \log \left(\left|\hat{H}_{t}\right|\right)+\epsilon_{t}^{\prime} \hat{H}_{t}^{-1} \epsilon_{t}\right]$. The highest value $(-1904.5)$ is obtained for the mGDCC, the smallest (-2000.3) for the standard DCC, and the mDCC is in the middle $(-1907.3)$. These log-likelihood values are all computed using the periodic congestion GJR models for the conditional variances and the VECM model for the conditional means.

\section{Short-term forecasts of Phelix futures covariance matrix}

Our ultimate objective is to provide forecasts of the volatility matrix of Phelix baseload futures. Covariance matrix forecasts can be used to compute joint density forecasts of electricity futures returns. From the forecasted joint probability distributions, the distribution of future portfolio returns can be derived and risk measures such as Value-at-Risk computed.

We give priority to short-run forecasting, where it makes sense to approximate the future unconditional covariance matrix by a constant. One could simply take the estimated unconditional matrix on the last day of the estimation sample. However, this procedure is problematic for two reasons: the nonparametric estimator is less accurate near the boundary of the observation sample, 
and for forecasting, the level of the unconditional covariance on the last day is not useful since the estimate is obtained using out-of-sample data. A solution is then to use a one-sided kernel. We follow an alternative method, where the future unconditional covariance matrix is approximated by replacing the Gaussian kernel by a bounded one (e.g. Epanechnikov kernel), and stopping the regression $h \times T$ days before the out-of-sample limit (with $h=0.09$, the optimal bandwidth for the Epanechnikov kernel, and $T$ the in-sample size). This ensures that the nonparametric regression is exclusively based on in-sample data.

For the conditional part, due to the non-linearity of the DCC process, there is no analytic solution for forecasting correlations over longer horizons than one day. Engle and Sheppard (2001) discuss two approximation methods to generate multi-step ahead forecasts. We limit ourselves to one-step ahead forecasts, for which the one-day ahead forecast of the covariance matrix is given by $\hat{H}_{t+1}=\hat{\Sigma}(t / T-h)^{1 / 2} \hat{G}_{t+1} \hat{\Sigma}(t / T-h)^{1 / 2}$, where $\hat{\Sigma}(t / T)$ is calculated using the Epanechnikov kernel.

We compute 130 one-day ahead forecasts for the variances and covariances of the baseload futures. The forecasts are all obtained using the estimates at the end of the in-sample period. With recursive estimation (adding one observation to the estimation sample each day so that parameters are daily updated), the mean squared forecasting errors (MSFE) are slightly larger and do not give a different message, so we do not show these results.

The forecasts (black lines) for six months (130 trading days) from 04.15.2010 until 10.15.2010 are illustrated in Figure 7 for the best performing model. Because of the lack of intraday data for futures prices, we cannot compare the forecasts with realized variances and covariances. Instead, we take the squares and cross-products of the VECM residuals as proxies for the variances and covariances, respectively.

We compare different specifications for the covariance matrix of Phelix futures in terms of MSFE in Table 4. The mGDCC model with day-to-delivery (p) and congestion (c) (pc-mGDCC) is the best performing model. The largest improvement comes with the mDCC model compared to the DCC model that ignores slowly evolving trends in volatilities and co-volatilities. The multiplicative generalized DCC model (mGDCC) and the day-to-delivery and congestion effects in volatilities only give small improvements. As expected, only the forecasts of short-term maturity products (month and quarter futures) are improved when incorporating the day-to-delivery effect (p-mGDCC). The congestion model for volatilities seems also to be more useful for short-term products, for which we observe the largest spikes in the conditional variances and covariances. In this case, the exogenous variables are able to capture, to some extent, the spikes that are induced by transmission constraints so that the congestion model is favored during more hectic times.

In risk management, the Value-at-Risk (VaR) is a widespread tool to measure the market risk associated to a portfolio. The VaR at level $p$ (e.g. one percent) of a Phelix baseload futures (long) 
portfolio at time $t$ with composition weight $w=\left(w_{M}, w_{Q}, w_{Y}\right)^{\prime}$ is given by

$$
\operatorname{VaR}_{t}(w, p)=w^{\prime} \hat{\mu}_{t+1}+\left(w^{\prime} \hat{H}_{t+1} w\right)^{1 / 2} z_{p}
$$

where $\hat{\mu}_{t+1}$ is the forecasted VECM mean and $z_{p}$ is the $p$-percent quantile of the Gaussian distribution. Since only a small part of return changes is explained by the conditional mean, the forecasted covariance matrix $\hat{H}_{t+1}$ is responsible for the largest VaR changes over time. From equation (11), the implication of the smaller forecasting error of the pc-mGDCC model for a higher accuracy of VaR calculations is clear. Capturing the dynamic dependence of electricity futures and some stylized facts of power markets in the covariance, the new model should achieve higher performance of risk measurement for Phelix futures portfolios.
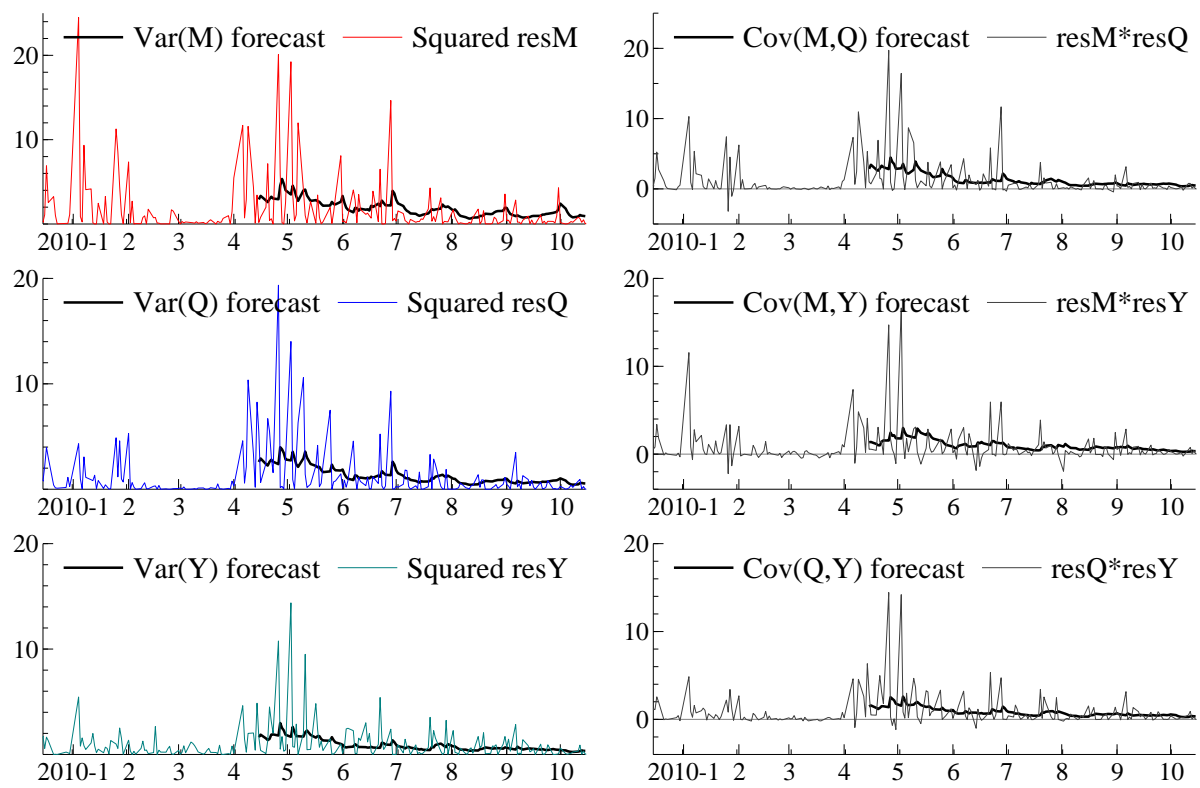

Figure 7: 130 day one-day ahead forecasts (periodic congestion mGDCC). The variance forecasts of contract $i$ is $\operatorname{Var}(i)$ forecast $=\hat{H}_{i i, t+1}$ (left panel). The covariance forecasts of contracts $i$ and $j$ is $\operatorname{Cov}(i, j)$ forecast $=\hat{H}_{i j, t+1}$ for $i \neq j$ (right panel). res $(i)$ are VECM residuals.

\begin{tabular}{c|cccccc|c} 
Model & $\operatorname{Var}(\mathrm{M})$ & $\operatorname{Var}(\mathrm{Q})$ & $\operatorname{Var}(\mathrm{Y})$ & $\operatorname{Cov}(\mathrm{M}, \mathrm{Q})$ & $\operatorname{Cov}(\mathrm{M}, \mathrm{Y})$ & $\operatorname{Cov}(\mathrm{Q}, \mathrm{Y})$ & Total \\
\hline DCC & 10.107 & 6.691 & 3.657 & 7.403 & 4.865 & 4.129 & 36.852 \\
$\mathrm{mDCC}$ & 9.552 & 6.307 & $\mathbf{3 . 4 9 6}$ & 7.011 & 4.637 & $\mathbf{3 . 9 3 2}$ & 34.935 \\
mGDCC & 9.520 & 6.317 & 3.502 & 6.995 & 4.619 & 3.945 & 34.897 \\
p-mGDCC & 9.257 & 6.306 & 3.511 & 6.955 & 4.616 & 3.956 & 34.601 \\
pc-mGDCC & $\mathbf{9 . 2 3 0}$ & $\mathbf{6 . 3 0 5}$ & 3.517 & $\mathbf{6 . 9 4 4}$ & $\mathbf{4 . 6 1 6}$ & 3.957 & $\mathbf{3 4 . 5 6 9}$
\end{tabular}

Table 4: MSFE (MSFE of 130 one-day ahead forecasts) 


\section{Conclusions}

We have presented a new multiplicative model for the multivariate volatility of Phelix baseload futures where the unconditional volatilities and correlations are allowed to change smoothly over time. The unconditional covariance is estimated by a nonparametric method, and its evolution is interpreted in the light of long-term factors observed in power markets. The confidence bands around the kernel estimates lead us to reject constant unconditional levels. The standardization of returns with the unconditional component offers several advantages. First, it leads to a substantial reduction of the persistence measure in conditional variances and correlations. In the case of Phelix futures, the reduction of the persistence implies the existence of unconditional variances in the multiplicative model. Second, the three-step estimation procedure allows us to identify factors explaining short-term variance and correlation dynamics.

In the conditional variance models, we introduce exogenous variables accounting for transmission shocks and the periodicity associated to month futures delivery. It is shown that futures respond to congestion with different markets according to their maturity. Using a generalized multiplicative DCC model, we also find different dynamics for the three conditional correlation processes of electricity futures.

The estimation method appears to be economically relevant for power markets. Kernel estimation of the smooth unconditional component is purely based on data evidence such that we do not need to identify the exact nature of long-term factors affecting electricity futures. On the other hand, the exogenous variables explaining short-term dynamics are more 'natural' fundamentals to identify, since they are linked to the physical power market.

Finally, one-day ahead forecasts are derived and a higher forecasting performance is achieved with the multiplicative DCC model compared to the standard DCC model that ignores the changes in unconditional volatilities and correlations. The periodic congestion model and the augmented DCC also reduce the forecasting error but their contribution is smaller in that respect. A next step is the application of the new multivariate volatility model for measuring the risk associated to Phelix futures portfolios. The higher forecasting performance of the multivariate multiplicative volatility model should be reflected in the accuracy of risk measures such as the Value-at-Risk.

Further research opportunities are left open. Firstly, the conditional normality assumption is primarily motivated by the possibility to decompose the DCC estimation into two steps. Distributions with fat tails may significantly improve the model fit and could be highly relevant for risk measurement. Secondly, the extension to more than three dimensions is also practically relevant. The inclusion of other markets or other energy products in the portfolio may give insights about causality and spillovers. Thirdly, the multivariate GARCH models could also be compared to multivariate stochastic volatility models. Finally, the new multiplicative DCC model should also be useful to model other financial returns that are subject to changing long-term trends. 


\section{References}

Aielli G. 2009. Dynamic conditional correlations: on properties and estimation. Technical report, Department of Statistics, University of Florence.

Alexander C. 2002. Principal component models for generating large GARCH covariance matrices. Economic Notes 31(2): 337-359.

Bauwens L, Laurent S, Rombouts J. 2006. Multivariate GARCH models: a survey. Journal of Applied Econometrics 21: 79-109.

Bauwens L, Preminger A, Rombouts J. 2010. Theory and inference for a Markov-switching GARCH model. Econometrics Journal 13: 218-244.

Bauwens L, Storti G. 2009. A component GARCH model with time varying weights. Studies in Nonlinear Dynamics \& Econometrics 13(2): Article 1.

Billio M, Caporin M. 2009. A generalized dynamic conditional correlation model for portfolio risk evaluation. Mathematics and Computers in Simulation 19(8): 2566-2578.

Bollerslev T. 1990. Modeling the coherence in short-run nominal exchange rates: A multivariate generalized ARCH model. Review of Economics and Statistics 72: 498-505.

Bosco B, Parisio L, Pelagatti M, Baldi F. 2010. Long-run relations in European electricity prices. Journal of Applied Econometrics 25: 805-832.

Cappiello L, Engle R, Sheppard K. 2006. Asymmetric dynamics in the correlations of global equity and bond returns. Journal of Financial Econometrics 4: 537-372.

Carnero A, Koopman S, Ooms M. 2007. Periodic heteroskedastic RegARFIMA models for daily electricity spot prices. Journal of the American Statistical Association 102(477): 16-27.

Colacito R, Engle R, Ghysels E. 2009. A component model for dynamic correlations. NYU Working Paper No. FIN-08-039.

De Jong C, Schneider S. 2009. Cointegration between gas and power spot prices. The Journal of Energy Markets 2(3): 27-46.

Doornik J. 2009. An Object-Oriented Matrix Language Ox 6. Timberlake Consultants Press.

Engle R. 2002. Dynamic conditional correlation: a simple class of multivariate generalized autoregressive conditional heteroskedasticity models. Journal of Business and Economic Statistics 20(3): 339-350.

Engle R, Kroner F. 1995. Multivariate simultaneous generalized ARCH. Econometric Theory, 11: $122-150$.

Engle R, Lee G. 1999. A long-run and short-run component model for stock return volatility. In Engle RF, White H (eds.) Cointegration, Causality, and Forecasting: A Festschrift in Honour of Clive W. J. Granger, chapter 20. Oxford University Press, 475-497. 
Engle R, Rangel J. 2008. The spline-GARCH model for low-frequency volatility anf its global macroeconomic causes. Review of Financial Studies 21(3): 1187-1222.

Engle R, Sheppard K. 2001. Theoretical and empirical properties of dynamic conditional correlation multivariate GARCH. NBER Working Paper No. 8554.

Geman H. 2005. Commodities and commodity derivatives, modeling and pricing for argiculturals, metals and energy. Wiley Finance.

Glosten L, Jagannathan R, Runkle D. 1993. On the relation between the expected value and the volatility of the nominal excess return on stocks. The Journal of Finance 48(5): 1779-1801.

Haas M, Mittnik S, Paolella M. 2004a. Mixed normal conditional heteroskedasticity. Journal of Financial Econometrics 2(2): 211-250.

Haas M, Mittnik S, Paolella M. 2004b. A new approach to Markov-switching GARCH models. Journal of Financial Econometrics 2(4): 493-530.

Hafner C, Franses P. 2009. A generalized dynamic conditional correlation model: simulation and application to many assets. Econometric Reviews 28(6): 612-631.

Hafner C, Linton O. 2010. Efficient estimation of a multivariate multiplicative volatility model. Journal of Econometrics 159(1): 55-73.

Haldrup N, Nielsen M. 2006. Directional congestion and regime switching in a long memory model for electricity prices. Studies in Nonlinear Dynamics \& Econometrics 10(3): Article 1.

Härdle W. 1990. Applied Nonparametric Regression. Cambridge University Press.

Janczura J, Weron R. 2010. An empirical comparison of alternate regime-switching models for electricity spot prices. Energy economics 32: 1059-1073.

Johansen S. 1991. Estimation and hypothesis testing of cointegration vectors in Gaussian vector autoregressive models. Econometrica 59: 1551-1580.

Knittel C, Roberts M. 2005. An empirical examination of restructured electricity prices. Energy Economics 27: 791-817.

Pelletier D. 2006. Regime switching for dynamic correlations. Journal of Econometrics 131: 445473.

Pilipovic D. 2007. Energy risk, valuing and managing energy derivatives. 2nd edition. McGraw-Hill.

Rangel J, Engle R. 2009. The factor-spline-GARCH model for high and low frequency correlations. Banco de Mexico Working Paper No. 2009-03.

Samuelson P. 1965. Proof that properly anticipated prices fluctuate randomly. Industrial Management Review 6: 41-49.

Silvennoinen A, Teräsvirta T. 2005. Modeling conditional correlations of asset returns: a smooth transition approach. SSE/EFI Working Paper Series in Economics and Finance No. 577. 
Silvennoinen A, Teräsvirta T. 2009. Multivariate GARCH models. Handbook of Financial Time Series Part 1: 201-229.

Tse Y, Tsui A. 2002. A multivariate GARCH model with time-varying correlations. Journal of Business and Economic Statistics 20: 351-362.

van der Weide R. 2002. GO-GARCH: a multivariate generalized orthogonal GARCH model. Journal of Applied Econometrics 17: 549-564.

Wilkens S, Wimschulte J. 2007. The pricing of electricity futures: evidence from the European Energy Exchange. The Journal of Futures Markets 27(4): 387-410. 


\section{SFB 649 Discussion Paper Series 2011}

For a complete list of Discussion Papers published by the SFB 649, please visit http://sfb649.wiwi.hu-berlin.de.

001 "Localising temperature risk" by Wolfgang Karl Härdle, Brenda López Cabrera, Ostap Okhrin and Weining Wang, January 2011.

002 "A Confidence Corridor for Sparse Longitudinal Data Curves" by Shuzhuan Zheng, Lijian Yang and Wolfgang Karl Härdle, January 2011.

003 "Mean Volatility Regressions" by Lu Lin, Feng Li, Lixing Zhu and Wolfgang Karl Härdle, January 2011.

004 "A Confidence Corridor for Expectile Functions" by Esra Akdeniz Duran, Mengmeng Guo and Wolfgang Karl Härdle, January 2011.

005 "Local Quantile Regression" by Wolfgang Karl Härdle, Vladimir Spokoiny and Weining Wang, January 2011.

006 "Sticky Information and Determinacy" by Alexander Meyer-Gohde, January 2011.

007 "Mean-Variance Cointegration and the Expectations Hypothesis" by Till Strohsal and Enzo Weber, February 2011.

008 "Monetary Policy, Trend Inflation and Inflation Persistence" by Fang Yao, February 2011.

009 "Exclusion in the All-Pay Auction: An Experimental Investigation" by Dietmar Fehr and Julia Schmid, February 2011.

010 "Unwillingness to Pay for Privacy: A Field Experiment" by Alastair R. Beresford, Dorothea Kübler and Sören Preibusch, February 2011.

011 "Human Capital Formation on Skill-Specific Labor Markets" by Runli Xie, February 2011.

012 "A strategic mediator who is biased into the same direction as the expert can improve information transmission" by Lydia Mechtenberg and Johannes Münster, March 2011.

013 "Spatial Risk Premium on Weather Derivatives and Hedging Weather Exposure in Electricity" by Wolfgang Karl Härdle and Maria Osipenko, March 2011.

014 "Difference based Ridge and Liu type Estimators in Semiparametric Regression Models" by Esra Akdeniz Duran, Wolfgang Karl Härdle and Maria Osipenko, March 2011.

015 "Short-Term Herding of Institutional Traders: New Evidence from the German Stock Market" by Stephanie Kremer and Dieter Nautz, March 2011.

016 "Oracally Efficient Two-Step Estimation of Generalized Additive Model" by Rong Liu, Lijian Yang and Wolfgang Karl Härdle, March 2011.

017 "The Law of Attraction: Bilateral Search and Horizontal Heterogeneity" by Dirk Hofmann and Salmai Qari, March 2011.

018 "Can crop yield risk be globally diversified?" by Xiaoliang Liu, Wei Xu and Martin Odening, March 2011.

019 "What Drives the Relationship Between Inflation and Price Dispersion? Market Power vs. Price Rigidity" by Sascha Becker, March 2011.

020 "How Computational Statistics Became the Backbone of Modern Data Science" by James E. Gentle, Wolfgang Härdle and Yuichi Mori, May 2011.

021 "Customer Reactions in Out-of-Stock Situations - Do promotion-induced phantom positions alleviate the similarity substitution hypothesis?" by Jana Luisa Diels and Nicole Wiebach, May 2011.

\section{SFB 649, Spandauer Str. 1, D-10178 Berlin http:/ / sfb649.wiwi.hu-berlin.de}

This research was supported by the Deutsche Forschungsgemeinschaft through the SFB 649 "Economic Risk".

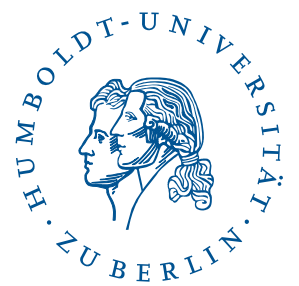




\section{SFB 649 Discussion Paper Series 2011}

For a complete list of Discussion Papers published by the SFB 649, please visit http://sfb649.wiwi.hu-berlin.de.

022 "Extreme value models in a conditional duration intensity framework" by Rodrigo Herrera and Bernhard Schipp, May 2011.

023 "Forecasting Corporate Distress in the Asian and Pacific Region" by Russ Moro, Wolfgang Härdle, Saeideh Aliakbari and Linda Hoffmann, May 2011.

024 "Identifying the Effect of Temporal Work Flexibility on Parental Time with Children" by Juliane Scheffel, May 2011.

025 "How do Unusual Working Schedules Affect Social Life?" by Juliane Scheffel, May 2011.

026 "Compensation of Unusual Working Schedules" by Juliane Scheffel, May 2011.

027 "Estimation of the characteristics of a Lévy process observed at arbitrary frequency" by Johanna Kappus and Markus Reiß, May 2011.

028 "Asymptotic equivalence and sufficiency for volatility estimation under microstructure noise" by Markus Reiß, May 2011.

029 "Pointwise adaptive estimation for quantile regression" by Markus Reiß, Yves Rozenholc and Charles A. Cuenod, May 2011.

030 "Developing web-based tools for the teaching of statistics: Our Wikis and the German Wikipedia" by Sigbert Klinke, May 2011.

031 "What Explains the German Labor Market Miracle in the Great Recession?" by Michael C. Burda and Jennifer Hunt, June 2011.

032 "The information content of central bank interest rate projections: Evidence from New Zealand" by Gunda-Alexandra Detmers and Dieter Nautz, June 2011.

033 "Asymptotics of Asynchronicity" by Markus Bibinger, June 2011.

034 "An estimator for the quadratic covariation of asynchronously observed Itô processes with noise: Asymptotic distribution theory" by Markus Bibinger, June 2011.

035 "The economics of TARGET2 balances" by Ulrich Bindseil and Philipp Johann König, June 2011.

036 "An Indicator for National Systems of Innovation - Methodology and Application to 17 Industrialized Countries" by Heike Belitz, Marius Clemens, Christian von Hirschhausen, Jens Schmidt-Ehmcke, Axel Werwatz and Petra Zloczysti, June 2011.

037 "Neurobiology of value integration: When value impacts valuation" by Soyoung Q. Park, Thorsten Kahnt, Jörg Rieskamp and Hauke R. Heekeren, June 2011.

038 "The Neural Basis of Following Advice" by Guido Biele, Jörg Rieskamp, Lea K. Krugel and Hauke R. Heekeren, June 2011.

039 "The Persistence of "Bad" Precedents and the Need for Communication: A Coordination Experiment" by Dietmar Fehr, June 2011.

040 "News-driven Business Cycles in SVARs" by Patrick Bunk, July 2011.

041 "The Basel III framework for liquidity standards and monetary policy implementation" by Ulrich Bindseil and Jeroen Lamoot, July 2011.

042 "Pollution permits, Strategic Trading and Dynamic Technology Adoption" by Santiago Moreno-Bromberg and Luca Taschini, July 2011.

043 "CRRA Utility Maximization under Risk Constraints" by Santiago MorenoBromberg, Traian A. Pirvu and Anthony Réveillac, July 2011.

\section{SFB 649, Spandauer Str. 1, D-10178 Berlin http:/ / sfb649.wiwi.hu-berlin.de}




\section{SFB 649 Discussion Paper Series 2011}

For a complete list of Discussion Papers published by the SFB 649, please visit http://sfb649.wiwi.hu-berlin.de.

044 "Predicting Bid-Ask Spreads Using Long Memory Autoregressive Conditional Poisson Models" by Axel Groß-Klußmann and Nikolaus Hautsch, July 2011.

045 "Bayesian Networks and Sex-related Homicides" by Stephan Stahlschmidt, Helmut Tausendteufel and Wolfgang K. Härdle, July 2011.

046 "The Regulation of Interdependent Markets", by Raffaele Fiocco and Carlo Scarpa, July 2011.

047 "Bargaining and Collusion in a Regulatory Model", by Raffaele Fiocco and Mario Gilli, July 2011.

048 "Large Vector Auto Regressions", by Song Song and Peter J. Bickel, August 2011.

049 "Monetary Policy, Determinacy, and the Natural Rate Hypothesis", by Alexander Meyer-Gohde, August 2011.

050 "The impact of context and promotion on consumer responses and preferences in out-of-stock situations", by Nicole Wiebach and Jana L. Diels, August 2011.

051 "A Network Model of Financial System Resilience", by Kartik Anand, Prasanna Gai, Sujit Kapadia, Simon Brennan and Matthew Willison, August 2011.

052 "Rollover risk, network structure and systemic financial crises", by Kartik Anand, Prasanna Gai and Matteo Marsili, August 2011.

053 "When to Cross the Spread: Curve Following with Singular Control" by Felix Naujokat and Ulrich Horst, August 2011.

054 "TVICA - Time Varying Independent Component Analysis and Its Application to Financial Data" by Ray-Bing Chen, Ying Chen and Wolfgang K. Härdle, August 2011.

055 "Pricing Chinese rain: a multi-site multi-period equilibrium pricing model for rainfall derivatives" by Wolfgang K. Härdle and Maria Osipenko, August 2011.

056 "Limit Order Flow, Market Impact and Optimal Order Sizes: Evidence from NASDAQ TotalView-ITCH Data" by Nikolaus Hautsch and Ruihong Huang, August 2011.

057 "Optimal Display of Iceberg Orders" by Gökhan Cebiroğlu and Ulrich Horst, August 2011.

058 "Optimal liquidation in dark pools" by Peter Kratz and Torsten Schöneborn, September 2011.

059 "The Merit of High-Frequency Data in Portfolio Allocation" by Nikolaus Hautsch, Lada M. Kyj and Peter Malec, September 2011.

060 "On the Continuation of the Great Moderation: New evidence from G7 Countries" by Wenjuan Chen, September 2011.

061 "Forward-backward systems for expected utility maximization" by Ulrich Horst, Ying Hu, Peter Imkeller, Anthony Réveillac and Jianing Zhang.

062 "On heterogeneous latent class models with applications to the analysis of rating scores" by Aurélie Bertrand and Christian M. Hafner, October 2011.

063 "Multivariate Volatility Modeling of Electricity Futures" by Luc Bauwens, Christian Hafner and Diane Pierret, October 2011.

\section{SFB 649, Spandauer Str. 1, D-10178 Berlin} http:/ / sfb649.wiwi.hu-berlin.de

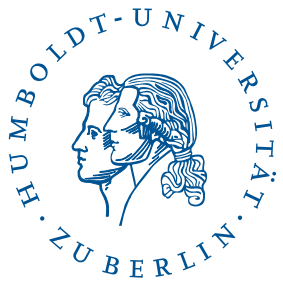

